\title{
EVALUATING THE DESIGN OF HOSPITALS WITHIN A PRACTICE ORDER NETWORK
}

\begin{abstract}
Design evaluation is a complex and rich social practice that is organised and distinguished by its practical understandings, rules, general understandings and teleoaffective structures. This praxiographic study of a major National Health Service (NHS) hospital project uses practice theory to investigate the concept of design evaluation as 'a practice'. By applying Theodore Schatzki's site ontology, design evaluation practices are revealed to respond to dynamic teleoaffective structures that highlight the role of both practical intelligibility and the intertwined impact of external policy stipulations. Through this theoretical lens, fresh insight into the actuality of NHS hospital design evaluation praxis is provided that questions some of the axioms upon which such processes are assumed to operate. In particular, the appropriateness of the decontextualised and deterministic processes currently found in UK Government design policy is questioned. It is posited that an approach to design evaluation grounded in Schatzki's practice theory has greater potential to improve the design quality of NHS healthcare buildings that could, in turn, improve patient healthcare outcomes.
\end{abstract}

Keywords: Design evaluation, NHS Design Quality Policy, Schatzki's practice theory, practical intelligibility, teleoaffective structures.

\section{INTRODUCTION}

Motivated by a desire to improve the design quality of National Health Service (NHS) buildings, NHS Design Quality Policy has been instigated upon stakeholders involved in the design and procurement of such facilities. Following Bryson, (2004) a stakeholder is defined here as a group or individual who can affect or is affected by the achievement of the NHS organisation's design evaluation objectives. NHS Design Quality Policy mandates positivist design evaluation instruments to capture stakeholder views (see for example NHS Scotland's Design Quality Policy, 2010). As such, they have been criticised for lacking an appreciation of the social nature of the activities that surround their use (O'Keeffe et. al., 2012). In order to better understand the effects of such instruments on the design process, we undertook a 20 -month longitudinal investigation into the day-to-day activities a major new NHS hospital project. The aim here was to better understand how studying the social activities and relations of those involved in design evaluation can be used to gain insight into the nature of design evaluation within such public sector projects. Of particular interest here is how the complex array of loosely coupled actors involved in such decisions shape such processes, and the role of design evaluation tools in shaping the decision dialogue through these encounters. To this end, and reflecting the so-called 'practice turn' in organization and management studies (Schatzki et al., 2001; Whittington, 2006; Feldman \& Orlikowski, 2011) we mobilised practice theory to provide a conceptual framework for the research design and to provide an analytical means of examining its empirical findings.

\section{THE NHS DESIGN POLICY LANDSCAPE}

In 2000, the NHS began a 'once in a life-time' national programme of capital investment into new hospitals. The programme built over 110 new hospitals, 749 primary care schemes and 2,848 general practitioner surgeries (Department of Health 
2007; Hare 2013). Consistent with the Labour party's ambitious public sector plans, in 2004 the NHS introduced a prescribed design quality policy, part of an earlier overarching 'modernising' manifesto of the time that remains in force today (The Department of Health, 2001). This policy, amongst a swath of others in education, social care and criminal justice sectors prescribes "not just what to, how to do it" but also "to ensure that it happens" (Davies \& Nutley, 2001, p. 86). With a neoliberalist outlook, this policy explicitly mandates the involvement of stakeholders in periodic design evaluation workshops. These workshops must, in turn, use prescribed design quality instruments (henceforth 'instruments').

This policy, (typified by the NHS Scotland's Design Quality Policy, 2010) - hereafter the NHS's 'Design Quality Project' (DQP) requires that design be evaluated at key stages of design progression that are referenced to the development of the project's 'business case' by means of design evaluation workshops. The detailed organisation and agendas of such workshops are also prescribed by the DQP. Reductive in nature, the instruments are attuned to quantitative methodologies (namely 'Achieving Excellence Design Evaluation Tool' (AEDET) and "A Staff and Patient Environment Calibration Toolkit ' (ASPECT)). They iteratively elicit stakeholder 'scores' of predicted design performance-in-use against predetermined criteria, derived from evidenced-based design and other notions of 'good' hospital design; themselves abstractions.

Ontologically, AEDET (NHS Estates Department of Health Estates and Facilities, 2008) and ASPECT (NHS Estates Department of Health Facilities and Estates, 2008) are similar. In aping the Design Quality Indicator (DQI) (Gann et al., 2003), AEDET is founded, theoretically, on the well-rehearsed Vitruvian notion that 'good' architectural design exhibits firmitas, utilitas and venustas (or, in DQI language, build quality, function and impact) and is therefore universal, rationalistic, atemporal and context-independent.

We have argued previously (O'Keeffe et al. (2012)) that a fundamental risk stems from the reductionist determinism of the DQP and its instruments. The positivist paradigm upon which such instruments are founded adopts an ontology incapable of recognising the complex social reality of design evaluation. Any visitor to a DQP design evaluation workshop is likely to note significant acts of communication between the stakeholders, along with a typical disorderly array of artefacts. Typically, such artefacts would include ad-hoc sketches, more formal architectural and engineering drawings on tables and walls, projected images and projection equipment, physical models, computers and computer generated visualisations and drawing utensils, amongst others. The social significance of such communications and how they may be mediated by the artefacts are overlooked by the instruments, as are many other social realities (such as, for example, the likelihood that such stakeholders will come from diverse backgrounds and will probably not have worked together before). Arguably, there is a danger that the instruments' preoccupation in determining such 'scores' distorts and flattens the ontology of design evaluation to the detriment of stakeholder reflection on the nature of the proposed design solution. Such a distortion is, in essence, an example of what has been termed an 'epistemic fallacy' (Bhaskar, 1978), that is to say conflating the knowledge of what is (an epistemological statement) for what is (an ontological statement) (Carolan, 2005, p. 395).

With the uncritical use of such traditional approaches in other construction related fields - see Sage et al, (2010) - it is not clear to whether its use in design evaluation is 
adequate. Slavish adherence to such a traditional approach runs the risk of generating a 'relevancy [sic] gap' (Sexton and Lu, 2009) between the theory and actual practice of design evaluation for those tasked with implementing the DQP. This would appear to run contrary to its aim of improving design quality of healthcare facilities. Thinking abductively, it would seem sensible to try an alternative theoretical and analytical approach towards design evaluation to that prescribed by the DQP. One such alternative would be to conceptualise design evaluation using practice theory, which refocuses attention on the social nature of organised activities and how these relations are mediated by the materialities within which they become enmeshed.

Although the use of practice theory to study organised activities has been growing since the nineties (Reckwitz, 2002; Schatzki, 2002; Schatzki et al., 2001), its application to construction remains nascent (Winter \& Smith 2006; Bresnen 2009; Bresnen 2007; Askland et al. 2013; Marshall 2014). This relative novelty warrants a brief examination of the distinguishing features of practice theory as an alternative to traditional approaches. Following this, we will demonstrate an application of a specific practice theory as originated by Schatzki to the design evaluation of a new NHS hospital project. Finally we will discuss the challenges and limits of such a new approach, together with its implications for the current NHS Design Quality Policy.

\section{DISTINGUISHING FEATURES OF PRACTICE THEORYAS AN ALTERNATIVE TO TRADITIONAL APPROACHES}

Practice theory is distinguished by its claims regarding what constitutes social life and where it is located (Reckwitz, 2002; Schatzki, 2005). As such, it recognises that "it is through action and interaction within practices that mind, rationality and knowledge are constituted and social life is organized, reproduced and transformed" (Schatzki et al., 2001, p. i). There are numerous different types of practice theory, distinguished principally by their ontological assumptions. A core concept for all practice theories however, is that they consider practices as embodied arrays of human actions and activities that are mediated by material objects and are centrally organised around a shared practical understanding. Practice theories insist that social life is not located solely within cognitive processes, communications (i.e. 'sayings') or solely within interactions (i.e. 'doings'), but instead that social life and practical knowledge are both intertwined with doings and sayings (i.e. routinised actions, networks and the material arrangements of things including artefacts and the performativity of humans). The term 'practical knowledge' considers knowing to be bound up with action and viceversa: knowing and doing are considered ontologically equivalent but analytically different. Practice theories thus seek to foreground 'know-how', nonprepositional and tacit knowledge, and illuminate the role and conditions of practical intelligibility, the common sense that drives an individual's actions.

Practice theories always foreground activity and performance in the study of practices. It is the 'doing' that is the basis of analysis: i.e. the practices not the practitioners involved. Practitioners 'carry' the practice (Reckwitz, 2002). As such, practice theories are primarily concerned with action and how such acts are achieved and not the individuals concerned.

Another important distinction is the epistemic role of theoretical knowledge in practice theory. Instead of considering knowledge a priori as the primary instrument available to inform action, a practice theory approach argues that it maybe more 
useful to think of any organised activity as a process of knowing involving the recursive articulation of knowledge. In addition, this process is intertwined with knowing derived from actually doing the activity, rather than as a pre-conditioning predecessor to the other. In other words, this approach allows us to think of practice not just as a process, but as something that humans do and, in doing, know and understand the practice. However, such an approach requires an understanding of the relationships between the ontology of the practice, prepositional knowledge, knowhow, teleology, and doing.

The Aristotelian concept of phronesis has distinctive features that underpin practice theory. Phronesis is a quality of mind (a virtue) that refers to practical wisdom whose aim is to produce action (praxis) that is informed by purposeful and value-driven deliberations. Practical wisdom is enacted by determining a morally right action in a specific situation. We must reflect upon the interplay between actions that might apply to the situation and the situation's unique features (Johannessen, 1990). Further, practical wisdom is both distinct from - and irreducible to - theory: it is primarily concerned with the particular - not, in Aristotle's words, with "open-ended contemplation about the universals" (Aristotle, NE, Book VI). As such, practice theories not only foreground action but also the values and sense of purpose that drives actions as part of any organised activity.

The role of reflection also differs in terms of source, content and effect between practice theories and traditional approaches. In traditional approaches, reflection involves 'stepping-back' and 'removing the self' from the on-going activity. Reflection is thus a calculative, detached and neutral action that typically goes towards transforming an abstract mental model of the physical phenomena (Geiger, 2009). By contrast, a practice theory perspective holds that because people and objects are inseparably entwined 'in-the-world', the idea of 'stepping back' from such unfolding processes is not possible (Schatzki, 2001, 2005). Reflection is considered instead to emanate from within the unfolding processes without resorting to detached mental models. This perspective reverses the focus of reflection, as in traditional approaches, from contemplation to action, particularly in complex situations that pursue novel responses and in which shared understandings are reframed as social interactions proceed (Zundel, 2012). Such reflection has significant epistemic potential in design evaluation activities within a practice theory perspective.

Bringing together the epistemic roles of theory, phronesis, praxis and reflection (collectively 'epistemic practice') inherent in practice theory perspective requires, as Nicolini $(2009$, p. 4) points out, the scrutiny of two practices at the same time: 'the epistemic practice' and the 'what' with which we are concerned.

Practice theories further distinguish themselves by their ontological heterogeneity. This means that a unified, single corpus of practice theory (Schatzki, 2002) cannot exist because, within such a corpus, individual practice theories would embody incompatible ontologies. The heterogeneity of practice theories emphasises the need to understand the similarities and differences between them, thereby avoiding any risk of combining different and potentially incompatible assumptions (Nicolini, 2012). If this is not done, methodological instruments could be adopted that do not cohere with the overlying ontological and epistemological stances of the selected practice theory perspective. This would, in turn, weaken the foundation of any resulting theoretical innovation (Grix, 2010). This has significant methodological implications for practice 
theory driven research, including the need to be explicit about the ontology of the chosen practice theory, so as to inform its epistemic practice.

Drawing together all of the above distinctive strands of practice theories, we adopt, along with Mol's (2010) suggestion, 'praxiography' as the preferred research technique (a technique defined here as being the skilful use of carrying out a method, as distinguished from merely following a method). Praxiography describes the overarching, distinctive and qualitative emic nature of practice theory driven research vis-à-vis traditional approaches. Identified in this way, praxiography provides a distinctive way of seeing and a way of being a practice theory driven researcher.

Resembling those analytical ethnographic techniques that also use theory driven approaches prior to entering the field (Snow et al., 2003; Whitehead, 2002), praxiography as a technique immerses the practice theory driven researcher into the praxis of organised activity and its 'situated' setting. However, whilst there are resemblances, praxiography is distinct from analytical ethnography in several respects: foregrounding the innate heterogeneity of the ontology of practice theory, and the materiality of practices, as already discussed, being some of them (Littig, 2013; Clever and Ruberg, 2014). Praxiography also resonates with Pink's critique that ethnography based on social interactionism is inadequate for the study of everyday life. Such approaches remain distanced from, rather than reflexively situated in, practices (Pink, 2012).

\section{MOBILISING SCHATKI'S PRACTICE THEORY}

Building extensively on Wittgenstein and Heidegger, Schatzki has, according to Nicolini (2013, p. 163), "offered one of the more explicit and clear illustrations of the implications of a practice-based approach". "Schatzki is a central interlocutor in current debates ... on practice theory" (Caldwell, 2012, p. 2). A prominent feature of Schatzki's work is its breadth and the extent of its convincing (and, indeed, at times polemic) critique of preceding practice theory luminaries such as Bourdieu, Giddens, Taylor, Laclau, Lyotard and Chantal, to mention just a few. It also critiques rival theories related to practice as a social phenomenon such as, for example, Actor Network Theory. For these reasons, and the explicitness and clarity of his terminology and illustrations about what a practice is and is not (Cox, 2012, p. 2), Schatzki's practice theory has been chosen to inform the epistemic practice of design evaluation as illustrated empirically below.

\section{Introducing Schatzki's site ontology: the "site of the social"}

According to Schatzki, the best way of approaching the topics that constitute social life (i.e. the nature of social existence, what it consists in, and how it may change) is to tie it to the "site of the social" (Schatzki, 2005). The site of the social, which denotes Schatzki's particular notion of site ontology within his particular practice theory, resonates with the Heideggerian phenomenological concept of Lichtung or a clearing: as in, "the clearing in a forest". Heidegger's phenomenology (1929) proposes that, before we can discern a subject and an object, we need a context against which entities can appear and make sense. That is to say, we need certain conditions so that anything can appear or come to light at all. Schatzki adopts this concept as the basis of his notion of site ontology (hereafter 'ontology') that distinguishes his particular practice theory from those of others. 
Schatzki further claims that his ontology comprises a mesh of orders and practices (Schatzki, 2005). Orders are 'material arrangements' of entities (things, people, artefacts), that are referred to in Schatzki's later works (Schatzki, 2010) as simply the 'arrangements' that typically would be found in any place of a given type and which constitute the organised activities of that place.

\section{The notion of practical intelligibility and the centrality granted to it in Schatzki's ontology}

In consideration of the governance of different actions that a person may perform at any moment, Schatzki grants ontological primacy to something called 'practical intelligibility', a 'watershed' feature of his ontology that he derived also from Heidegger and that distinguishes his practice theory from that of others (Nicolini, 2012, p. 164). "Practical intelligibility is what makes sense to a person to do" (Schatzki, 2002, p. 75). Schatzki stresses however that practical intelligibility is a) not the same as rationality, as a phenomenon it "can diverge" from rationality, and b) as a phenomenon is it not the same as normativity: "what makes sense for someone to do is not the same as or what is or what seems to be to the actor to be, appropriate, right or correct" (Schatzki, 2002, p.75). Nicolini cites smoking as an example of the latter (Nicolini, 2012). This notion is central to Schatzki's ontology because "practices constitutes horizons of intelligibility, and allow us to respond to different matters in different ways" (Nicolini, 2012, p.164). Schatzki (2002, p.75) argues that practical intelligibility is an individualist phenomenon and consists principally of the features possessed by, or that may be ascribed to, individuals, such as a person's goals, affectivity and the projects/tasks that s/he is pursuing.

\section{Schatzki's ontology: two notions of practice}

Putting aside, for the purposes on his ontology, the "notion of practice as learning how or improving..." by repetition or development (Schatzki, 1996, p.89), Schatzki's ontology goes on to provide two other notions of practice pertinent to this study. First, he considers practice a "temporally unfolding and spatially dispersed nexus of doings and sayings" (Schatzki, 1996, p. 89). This notion "embraces two overall dimensions: activity and organisation" (Schatzki, 2002, p.71). The second considers it "that of a performing an action" (Schatzki, 1996, p. 89-90; Schatzki, 2002).

\section{Design evaluation as a practice as 'doings and sayings'- linked by four 'avenues'}

To be recognised (a prerequisite to the researcher's observation) as a practice, 'doings and sayings' must form a nexus. Schatzki considers a nexus to arise when practices become linked by four "avenues" (1996, p. 89) or "dimensions of the organisation of practices" (Schatzki, 2001, p.53). Illustrated in the context of design evaluation, they are: (i) 'practical understandings' (such as knowing how to do things like reviewing design drawings and proposals); (ii) 'rules' (such as the explicit instruments and policies that stipulate design and design evaluation such as, for example, mandatory design standards and the DQP); (iii) 'teleoaffective structures' (namely, the overarching purpose, mood or feelings of the stakeholders); and (iv) 'general understandings' built from reflexive understandings and practical intelligibilities of the stakeholders (Schatzki, 2005) developed from their involvement in successive design evaluation workshops (for example, their progressive understanding of how the proposed design will impact on how a new hospital can be used to treat patients). These four organisational dimensions will be used as a framework to analyse the 
design evaluation practice of the stakeholders, illustrated in the empirical examples below.

\section{Methodological implications of Schatzki's ontology for studying design evaluation}

Two methodological tasks are inferred from Schatzki's site ontology: the need to identify the site and the practices within it; and the need to identify the practicearrangement bundles of which those practices are part. Arrangements - (see above) are entities (things, people, artefacts). A bundle is a set of linked practices and arrangements. Schatzki contends that researchers do not need to track and register the "potentially labyrinthe complexity of bundles, nets of bundles and so on" but simply need an understanding of "social phenomena and their workings couched in terms of referring, not to details of the practice-arrangement bundles but to entire formations and their relations" (Schatzki, 2005, p. 477).

\section{APPLYING SCHATZKI'S ONTOLOGY TO THE DESIGN EVALUATION OF NHS HOSPITALS}

To approach design evaluation as a practice it is first necessary to identify the site of design evaluation. Before we can discern a 'designer' or a 'design evaluator' as a subject and, say, a design drawing or computer generated image as an object, we need a context to observe empirically. In Schatzki's words, "Spaces qua openings or mediums are pre-eminently qualified to be something where, and as part of which, events occur and entities exist." The design evaluation workshop as mandated by the DQP ideally constitute such a clearing - the 'site' in which the evaluation practices of socialised actors provides a background understanding of what counts as objects, what counts as subjects and, thereby in terms of Schatzki's ontology, what counts as 'real'. As we will demonstrate below, creating a new hospital building through structured processes of procurement, design and construction provides numerous other design evaluation 'sites', which are thus available to the praxiographic researcher within established project management regimes. This is an important distinction and point of departure from the more constrained use of the instruments as envisaged by the DQP, and thus represents an wider opportunity to empirically access the actual day-to-day design evaluation activities of the stakeholders.

This insight immediately divides sites of design evaluation into those formally prescribed by the DQP and others that sit outside such policy stipulations. In Schatzkian terms, all such sites, humans, artefacts (man-made objects such as drawings, projectors and computers) and objects (entities whose being is not a result of human activities) intertwine and mesh with other as an example of a practice arrangement to shape design evaluation practice. They mould the practical intelligibility of the actors involved and bundle with other practice arrangements associated with design evaluation, all within a constellation of linked bundles that constitute the NHS project and the NHS organisation within which such organised activities reside.

\section{Viewing design evaluation 'sites' within a socio-technical regime}

Sensitising the research methodology towards Schatzki's ontology, Schatzki suggests that projects to be considered as socio-technical regimes (Schatzki, 2011). Described non-technically, the socio-technical regime applicable to design evaluation sites within a new NHS hospital project under investigation include: 
- the Health Board client (Holland, 2010);

- the consortiums of companies and their supply-chains bidding to provide the project (Carrillo, 2006);

- external government and local authority agencies;

- $\quad$ established 'models of care systems' (Anthony \& Hudson-Barr, 2004; Parand et al., 2014) for delivering healthcare services;

- the Health Board's myriad of other suppliers;

- extant government regulations including those for example fire and safety;

- the professional and other (for example trade union) associations of the stakeholders;

- other external stakeholders such as local industries, businesses and community groups, patient groups and their representative bodies;

- local infrastructure systems such as gas, electricity, water and telecommunication systems serving the hospital;

- other Health Boards, and other hospitals and healthcare facilities.

These entities represent organisations, rules, and material networks. Their configuration forms a socio-technical regime or, in ontological terms, they form a practice-arrangement bundle (see Schatzki, 2005). The critical reflection here, on this contextual complexity is, then, that design evaluation policy is inextricably linked and also subject to numerous external stipulations emanating from such entities. Such stipulations are examined later in the empirical illustration relating to consultant's offices.

\section{AN ILLUSTRATIVE DESIGN EVALUATION EPISODE -THE DESIGN EVALUATION OF CONSULTANT'S OFFICES}

The following findings typify the thematic insights emerging from the implementation of Schatzki's practice theory in relation to the consultant's offices. It is but one example of a design evaluation practice episode (i.e. design evaluation activity focused on a specific physical space designed for a specific function within the overall facility) selected from an ongoing Schatzkian-based praxiographic study of a large ( $£ 250$ million / €298 million) new NHS acute hospital project by a Scottish Health Board, (hereafter the Project).

Table 1 presents a concise summary of all the Project's phases observed to date, and cites the key design evaluation stakeholders involved in the corresponding phases practice of design evaluation of the Project together with timeline and the associated principal design activity.

<Table 1 Fieldwork Observation Phases insert above here>

The numerous design evaluation events (i.e. AEDET design evaluation workshops and far more numerous additional design evaluation meetings) took place in various places, including dedicated physical meeting rooms, a dedicated dialogue suite (for those design evaluation events during and the competitive dialogue phase) and also at lecture theatres in the Board's Education Centre. Common artefacts (such as computers, projection equipment, laser pens, teleconferencing equipment, meeting tables, audio recording equipment, drawings, physical models, material samples, physical mock-ups, virtual computer models and computer-generated images) were used consistently and constantly during all of the design evaluation events together with various document templates to capture evaluation comments and feedback. 
Within the progression of the Project, the episode for the consultant's offices took place iteratively during three distinct procurement phases. First, during developing the reference design (reference to Phase B in Table 1) prior to entering Competitive Dialogue. Secondly, during Competitive Dialogue (refer to phases $\mathrm{C}$ to $\mathrm{G}$ inclusive in Table 1). Thirdly, and most recently in October 2014, during Preferred Bidder toward Financial Close (refer to phase $\mathrm{H}$ in Table 1) when finalising the preferred bidder's design prior to financial close. Observations associated with the episode for the consultant's offices therefore spanned several project phases and different bundles of design evaluation practice.

\section{Principal methods used for data collection}

Participant observation (Marshall and Rossman, 1989) was the principle method used during the consultant office episode. Reckwitz has observed that, to some degree, participant observation, with its direct ability to allow audio and or video recording is the most effective method of praxiography (Reckwitz, 2008, p.196). Paying particular attention to the presence of any "arresting moments" field notes were taken throughout the episode, during and immediately after each design evaluation event. "Arresting moments" are moments that stakeholders can experience following instances of when their previously taken-for-granted beliefs are disrupted whilst performing a practice. Such moments can open up new possibilities to the stakeholders for future practices. See Beech et al, (2012) for an empirically informed and theoretical conceptualisation their qualities and how they promote reflexivity in practices (such as design evaluation). Audio recording was used to ensure reliability in data collection (Perakyla , 2004, p. 299). Participation observation during this particular episode allows exposure to Schatzki's four avenues at the nexus of the 'doings and sayings'. Following reflection on the researcher's initial data, the additional method of 'confrontation' interviews (see Lahlou, 2011) was subsequently utilised with the clinicians, members of the design evaluation team and the executives. Space does not permit a full account of the role and benefits of confrontation interviews - see Lahlou (2011, p. 617).

\section{Data Analysis and Representation}

Data analysis was initially tentative and exploratory. By focusing on the 'doings and sayings' of the design evaluation practice, which surrounded the researcher, he sought to sensitise himself to which of those doings and sayings were coalescing into nexuses. This approach, coupled with the exercise of the researcher's reflection and reflexivity (the latter using Bourdieu's (2003) 'participant objectivation') provided a sense of and insight into the praxis of routine day-to-day activities associated with the consultant offices' design evaluation episode.

\section{A note on project objectivation utilised as the basis of reflexivity}

The researcher acts as the Board's Project Director for the delivery of the Project against the timescales set by the Board in conjunction with SFT since phase A (see Table 1 above). The influence of this role and of potential personal bias during the research are acknowledged as a matter of potential concern (Shipton et al., 2014). To address this concern, the researcher used Bourdieu's notion and process of participant objectivation, (seen as an essential part of praxiography) which requires the researcher to reflexively consider his background, age, class, social trajectory, gender, nationality when interpreting the data. In particular, with this background reflexive contemplation established, particular social interactions between the stakeholders (e.g. the arresting 
moments) could be analysed with at least an awareness of the potential influence of personal bias of the researcher.

\section{Data Representation}

Czarniawska's (2007) narrative approach guided the researcher's write-up of a short vignette (Hughes and Huby 2002; Balogun and Rouleau 2007; Jenkins et al. 2010) to describe the unfolding of the design evaluation practice during the episode (see below). This particular vignette is framed by a preceding prologue (used here to locate the prior situation that led up to the consultant's offices design evaluation events during phase $\mathrm{H}$ ) and an epilogue within which reflective discussion takes place.

\section{Prologue to illustrative vignette for the design evaluation events of the consultant's offices (during phase $H$ )}

To begin with, it should be pointed out that the Board's reference design in relation to the layout of the offices was mandated both by the Board's executives and as an external stipulation manifest in SFT's publication "What Can We Do With the Office" (Scottish Futures Trust, 2012) to be strictly and non-negotiable as open-plan offices. It was in these terms that the reference design (as evaluated using AEDET) was presented to the hospital's clinical consultants (hereafter 'consultants') during phases A to $\mathrm{C}$, and as the basis of the Board's Scottish Government approved Outline Business Case (OBC). Whilst this was the subject of debate and explanation amongst the consultants, further overarching project stipulations (externally imposed, such as the need to progress the project against its onerous programme and affordability constraints) prevailed. Critically, at this stage, it should be noted that all of the consultants' representatives agreed to open-plan offices so long as they had separate meeting rooms (for any necessary confidential discussions with patients by consultants) and with break out spaces for less formal interactions. The reference design thus served for the bidders as a 'boundary object' during the Competitive Dialogue phase for the consultant's office (Star and Griesemer 1989; Luck 2010). One of the two bidder's, that later turned out to become the Preferred Bidder (PB), retained the open-plan offices as part of their design.

During phase $\mathrm{H}$ however, and following further design evaluation with the hospital consultants' workstream, a 'divergence of views' about the use of open-plan offices became apparent. First, as feedback to certain members of the Board's project team, and, then by means of what appeared to be a carefully orchestrated series of emails sent to the Board's Medical Director citing Jeremy Paxman's (a prominent UK boardcaster and journalist) proclamation of 'If I was King for a day I would ban Open Plan offices' (Paxman, 2014). Tensions were riding high. This was a fundamental shift in the Board's previously agreed design brief and the consultants' previously agreed position to accept open-plan office as noted above. The PB and the Board's project team were concerned over the impact on costs and, most importantly, impact on reaching Financial Close. The Board's Executives were alerted, and, sensing a 'revolt' by the consultants, the Chief Executive and the Medical Director immediately agreed to the hospital consultant's demands for an evening 'summit' meeting in the Board's Education Centre on 16th October 2014. All of the hospital's senior consultants were invited via email, together with several senior Executives of the Board, and the Project Director and other members of the Board's design evaluation team for the project 
attended this crucial meeting - with a single item agenda - a potential scene of confrontation (as good example of matters not contemplated by the DQP) was set..

The Executives arrived early and first in the stark and brightly lit Education Centre Lecture Theatre. A 'mock-up' of a consultant's office was improvised on the floor.. One of the executives addressed the gathering - 'good evening' and then dutifully went through a rehearsed PowerPoint presentation commencing with the previously agreed reference design solution (open-plan offices with space for 6 consultants) and then going through a series of 8 options, using a laser pen on the large projected images on the lecture theatre's huge screen. An hour passed and with the last slide the event was opened up to the consultants to comment.

A senior surgeon commenced immediately articulating his needs, which after complaining that "he has never been consulted about office space" argued for private space (i.e. single person offices) for "delicate and confidential patient discussions"; other consultant's followed each carefully -as if somewhat rehearsed-setting out in logical, rational and persuasive terms their needs for space, not only for confidentially but for the need "not to be distracted when making important clinical decisions"; "not to be distracted by colleagues in 'social talk'- which is worse if you actually get on with your colleague"; "it will be just impossible to work in open-plan"; some consultants were very animated - a few of least walked out into the floor area and started moving the mock up around to obtain a sense of how many 'single offices' could be squeezed into the area; others insisted on challenging the layouts on the screen using the laser pen. Others were more conciliatory - speaking about how, if operational rotas were managed, then 'pairs' of consultants could be grouped so that they would not ordinarily need to be in the same offices at the same time. Others were far more blatant: "I'd rather be in a 3 square meter area office with no windows than in an spacious open-plan office"; another senior anaesthetist, dressed in his blues from the operating theatre began his argument "I am a consultant too, I have training commitments with medical students - I can't do this in open-plan offices", he then finished his comments, with a dead pan expression saying that "....anyway I'm an antisocial bastard and I fart too much - I've got to have my own office". This personal revelation injected some levity into what was becoming a tense situation, reflected in the facial expressions, and, by this stage visible fidgeting from the Executives present, for, at least an hour of this constant and staged bombardment went on. Little technical discussion ensued, some of the consultant's suggestions on the layouts were immediately countered by constraints imposed by fire and other safety constraints as advised by members of the Board's design team present at the meeting. The Executives laboured the fact that by reducing the office occupancy downward from 6 to effectively 4 spaces would have a 'knock-on' effect in terms of extra ventilation, light and space needed to be sacrificed elsewhere as the option to increase overall floor plate of the hospital would not be acceptable to SFT $T^{l}$.

As time worn on it was clear that no single consensus was emerging. After this flurry of 'doings and sayings' the pace of exchanges subsided... then one of the consultants joked "has breakfast been ordered": we were now heading towards $10 \mathrm{pm}$. Then, one

\footnotetext{
${ }^{1}$ SFT stands for the Scottish Futures Trust. It is an independent company, established by the Scottish Government in 2008 with a responsibility for delivering value for money across all public sector infrastructure investment.
} 
of the Executives, increasing frustrated with the proceedings muttered "right I am going to call it". At this moment, another senior surgeon stood up and said "Look I came into this meeting because of my concerns about open-plan offices. I cannot accept them, ideally I would like to have my own private office. I came here determined to get a single office, but perhaps the two-person office arrangement could work if the rotas could be sorted out". The Executive who was about to "call it" sensed an opportunity for compromise. A brief silence ensued. Another consultant agreed with the surgeon. Another Executive offered the 'two-person office' as "the right way forward for everyone, complete with a window, bespoke office furniture and adjacent break out spaces". A 'deal' was struck. The meeting was ending. We all started to move towards the exit door, as I walked out with one of the Executives he turned and with a relieved expression raised his right hand---his fingers were crossed!---as if to say 'that was a close call'....

\section{Epilogue to illustrative vignette for the Offices (during phase H)}

A Schatzkian interpretation reveals that the 'site' of this organised activity: an instance of the practice of design evaluation, which comprise 'doings and sayings'. These are linked as a nexus with the consultants, the Board's Executives and members of the Board's project team present in the Board's Education lecture theatre. There is no apparent privileging of 'doings' over 'sayings'. The embodied actions of some of the consultants; walking about the floor, physically moving items in the mock up, pointing, facial expressions and laughter: all registered as just as important as what was said. The, by now, 'usual' arrangements in terms of artefacts were employed references to drawings, use of projection equipment, laser pens, mock up, screens etc.

In terms of 'rules' (recall as one of Schatzki's four 'avenues') operating in a Schatzkian analysis, the fact that a 'summit' meeting was organised at short-notice provides an example of this. Other relevant examples of rules referred to compliant space standards for offices and references to building regulations, fire, health and safety standards.

'Practical understandings' (recall as another of Schatzki's four 'avenues') were evidenced in the interactional order of the 'doings and sayings'. Anticipated 'professional courtesy' was extended; examples of over-speaking or 'gain-saying' interruptions were few and far between. At a technical design level, however, the exchanges were largely rudimentary in nature. The consultants were not really concerned about floor areas, ventilation or window constraints in terms of planning application consequences. Their focus was firmly fixed on 'removing the open-plan option' altogether. The critical observation here is that the practical understandings were not in themselves 'guiding' the underlying capacity for the action involved in the meeting. Instead, they served to assist the practice by knowing how to react to certain questions or decisions, but not to fundamentally control it.

In relation to Schatzki's notion of 'general understandings' (as another one of Schatzki's four avenues), this was manifest in the conduct of the meeting, with due respect given to 'proper' consultant and management interactions aimed ultimately towards the progress of the new hospital as an item of significant strategic importance to the Board and the local acute health care system.

The nexus of 'doing and sayings' highlights, via teleoaffective structures (as defined previously), significant changes to normative aspects of the offices' design evaluation, in comparison to the earlier to the current phase. In the earlier phases the specific direction and purposiveness was very much grounded in progressing with the concept 
design and OBC approval. By the time it reached this third episode however, the influence of the "negotiated order", a term coined by Strauss in his seminal study of hospitals and clinicians (Allen, 1997; Baszanger, 1998; Davies and Powell, 2007) to describe the consultants' power and influence, is much in evidence. The use of such power and influence is yet another matter that is not covered by the DQP and is a good example of the 'politics of design' in action - see Schmidt et al, (2012).

The most striking constitutive aspect of this evaluation is the practical intelligibility exhibited by the consultants and the executives. Clearly dominant in the initial stages of the meeting was the emotions and goal-orientated behaviour of, on the one hand, of individual consultants pressing their cases to remove, initially at least, the previously agreed 'open-plan' configuration and, on the other hand of the executives, to 'contain' such ambitions to prevent any additional capital or design costs accruing from the PB, (whose negotiation position is now clearly strengthen at this stage of the procurement). Whilst rehearsed, it was perhaps surprising that the consultants did not resort to for instance recently published studies that have raised concerns about open plan offices on productivity - for example see (Kim and de Dear, 2013) but their analogies and references to 'typing pools and 'battery hens' pointed to a more basic concern about their need for privacy. In terms of practical intelligibility, this Schatzkian notion effectively governs action; it was evident that open-plan offices simply 'did not make sense' to the great majority of the consultants present and was driving their actions at the meeting. This, even though they were aware that this was not expected or normative in terms of the SFT and Executive's mandated. As the meeting progressed, the level of contestation reached a critical point. A consultant expressed the opinion that the two-person offices could be an acceptable option, which the other consultants quickly reinforced, followed swiftly in turn by the Executive. This is an example of an "arresting moment": a moment of reflexivity in the minds of those present that opened up the prospect of a new possibility -the twoperson office-as a mutually acceptable new solution and way forward. Notice that the arresting moment was preceded by a period of seemingly entrenched views and heightened emotions and immediately followed what was in effect a disruption to the design evaluation process of the episode. During this arresting moment a reflexive realisation, and new knowledge was revealed to those present, that an alternative way was available. The arresting moment modified the stakeholder's practical intelligibility. It re-established a 'social order' in the, up to this point, increasingly strained relationship between the consultants and the others present at the meeting. The example also illustrates Schatzki's later notion of practice: human activity should be understood as an indeterminate temporal-spatial event. It was only in the "arresting moment" that what the participants did and why they did it revealed itself. Stated in Schatzkian temporal-spatial terms, the initial consent of the consultants in the earlier phase of the project did not predetermine the outcome of the current episode, thus providing an empirical example of "an inherently temporal-spatial happening that is not, in an important regard, pinned down by what precedes it" (Schatzki, 2010, p. x). Finally, the reference to operational rotas, as means of facilitating the outcome of design evaluation towards two-person offices, offers an interface to another set of practice arrangements -those of the consultant's day-to-day clinical practices. This interface illustrates that design evaluation sits along and indeed is part of mesh or bundle of practice-arrangements.

Immediately subsequent to this event, an instruction was given to the Preferred Bidder to modify the design according to the consensus set out above. By way of 
triangulation, the researcher held two, albeit brief, confrontation interviews with a consultants and an executives. Two points emerged from these interviews. First was the view that, only when the 'reality' of the progress of the design of hospital and of the consultant's offices were evident, that some of the consultants realised the "hospital was really happening" and that it "dawned upon them to act to get their offices sorted out". A second viewpoint noted that, with a high consultant vacancy rate, a demonstration of the 'power' could be exercised by senior clinicians. It indicates that space, and in particular clinical space, is regarded as a protected territory, a marker of professional boundaries by clinicians, not as merely a resource.

\section{CRITICAL REFLECTION}

\section{Insights into the actuality of design evaluation 'in-flight'}

The vignette empirically illustrates the 'actuality' or the "complex social processes" (Cicmil et al., 2006, p. 675) of design evaluation 'in-flight' that capture the flow of the 'situated' event. The practice theory analysis vividly reveals the significant extent to which social interactions, by way of 'doings and sayings', and artefacts, shape the outcomes of such events. Events that, in turn, bear directly on the design quality of the consultant's offices. It is notable that the instruments of the DQP are silent about such matters. The strength of opinions and emotions, which surfaced immediately prior to the arresting moment, supports the notion that the study of the social nature of such activities can provide insight into the relationship between design quality and design evaluation. Abductively reviewing the episode serves as a reminder that design evaluation cannot be regarded as concluded at any given point, and that, in practice, design evaluation continues, over the duration of a project, to be an "unfolding ontology" (Knorr Cetina, 2001, p. 190).

\section{Limitations of Schatzki's perspective: potential areas of ontological refinement for future research into design evaluation}

To date, we have revealed potential areas of theoretical development via the dialogical interplay between the empirical findings. The discussion below is focussed on some specific limitations of Schatzki's practice theory.

Invoking practical reflexivity and the role of "arresting moments" in design evaluation

Thus far, numerous other instances of "arresting moments" have been observed in addition to those illustrated in the vignette. Whilst Schatzki refers to the role of contested relations, Beech's et al (2012) notion of arresting moments more sharply foregrounds this phenomenon in relation to design evaluation. Synthesising Beech's notion with Schatzki's underlines the significance and importance of contestation and conflict during episodes of design evaluation practice. The study has shown that analysing such 'arresting moments' invokes practical reflexivity (Gorli et al., 2015), not only at a personal level, but also between the stakeholders. Design evaluation practices are thus not only based on shared understandings, rather a more nuanced view, which appreciates the reality of such practices that include the unpredictable presence of such conflicts. This provides a potentially valuable insight into the emotions and tacit knowledge of the stakeholders.

\section{The role of artefacts in design evaluation}

Reckwitz points out “things" (i.e. artefacts) are largely missing in Schatzki's practice theory (A. Reckwitz, 2002a, p. 21). Artefacts are a key element in the arrangements 
observed during design evaluation and resonate with the work of other theorists as objects in design (Eckert and Boujut 2003; Comi and Eppler 2011; Ewenstein and Whyte 2009). In contrast to Schatzki, Reckwitz advances the notion of "material understanding" as another potential dimension of linkage to 'doings and sayings' and this provides potential for further empirical investigation.

\section{The role of external stipulations in design evaluation}

With respect to the consultant's offices, external policy stipulations such the prevailing Government policy for offices in public buildings and compliance with mandatory design standards (e.g. for fire and building regulations) exert a major influence on design evaluation, an aspect underrepresented in Schatzki's practice theory. This too warrants further examination as the study proceeds and suggests, abductively, that coordination theories (for example those advanced by Bechky (2006)) can provide further empirical purchase on the actuality of design evaluation for NHS hospitals.

\section{CONCLUSION}

The application of Schatzki's practice theory to a particular design evaluation episode reveals both the constitutive role of practical intelligibility, and the implications of external policy stipulations on the day-to-day co-ordination of design evaluation practices. The epistemic use of artefacts in design, and the reflexive practical significance of "arresting moments", also act to order the design evaluation process in ways which stand in stark contrast to the highly ordered perspective conveyed in design quality evaluation policy and the DQP in particular. The insights provided by a Schatzkian practice theory perspective can act to sensitise designers and evaluators to crucial phenomena that are not emphasised by existing NHS design quality policy regimes. Moreover, they might foster a deeper, reflexive understanding of the dynamics of design and design evaluation in ways that instruments of current NHS design policy overlook.

\section{REFERENCES}

Allen, D., 1997. The nursing-medical boundary : a negotiated order? Sociology of Health and Illness, 19(4), pp.498-520.

Anthony, M.K. \& Hudson-Barr, D., 2004. A patient-centered model of care for hospital discharge. Clinical nursing research, 13(2), pp.117-36.

Askland, H.H., Gajendran, T. \& Brewer, G., 2013. Project organizations as organizational fields: expanding the level of analysis through Pierre Bourdieu's Theory of Practice. Engineering Project Organization Journal, 3(2), pp.116-126.

Balogun, J. \& Rouleau, L., 2007. EXPLORING MIDDLE MANAGERS'STRATEGIC SENSEMAKING ROLE IN PRACTICE, London UK.

Baszanger, I., 1998. The Web of Negotiation: Qualitative Sociology and Interactionism: Papers by Anselm Strauss, 1917-1996. Symbolic Interaction, 21(4), pp.353-378.

Bechky, B. a., 2006. Gaffers, Gofers, and Grips: Role-Based Coordination in Temporary Organizations. Organization Science, 17(1), pp.3-21. 
Beech, N. et al., 2012. Arresting moments in engaged management research. Management Learning, 44(3), pp.267-285.

Bhaskar, R., 1978. A Realist Theory of Science 2nd ed., Brighton, UK: Harvester Press.

Bourdieu, P., 2003. PARTICIPANT OBJECTIVATION *. Journal of the Royal Anthropological Institute, 9(April 2002), pp.281-294.

Bresnen, M., 2009. Living the dream? Understanding partnering as emergent practice. Construction Management and Economics, 27(10), pp.923-933.

Bresnen, M., 2007. The Practice Turn in Organisational Studies and Construction Management Research. In W. Hughes, ed. CME 25 Conference: Construction Management and Economics, Past, Present and Future, 16-18th July. Reading: University of Reading, pp. 1747-1756.

Bryson, J.M., 2004. What to Do When Stakeholders Matter -Stakeholder Identification and Analysis Techniques. Public Management Review, 6(1), pp.21-53.

Carolan, M.S., 2005. Society, Biology, and Ecology: Bringing Nature Back Into Sociology's Disciplinary Narrative Through Critical Realism. Organization \& Environment, 18(4), pp.393-421.

Carrillo, P., 2006. A Knowledge Transfer Framework : the PFI context. Construction Management and Economics, 24(10), pp.1045-1056.

Cicmil, S. et al., 2006. Rethinking Project Management: Researching the actuality of projects. International Journal of Project Management, 24(8), pp.675-686.

Clever, I. \& Ruberg, W., 2014. Beyond Cultural History? The Material Turn, Praxiography, and Body History. Humanities, 3(4), pp.546-566.

Comi, A. \& Eppler, M.J., 2011. Assessing the Impact of Visual Facilitation on InterOrganizational Collaboration : An Experimental Study. Journal of Universal Computer Science, 17(10), pp.1430-1454.

Cox, a. M., 2012. An exploration of the practice approach and its place in information science. Journal of Information Science, 38(2), pp.176-188.

Czarniawska, B., 2007. Shadowing and other techniques for doing fieldwork in modern societies, Malmo: Liber and Copenhagen Business School Press.

Davies, H. \& Nutley, S., 2001. Evidence-based policy and practice: moving from rhetoric to reality. In Third International, Inter-disciplinary Evidence-Based Policies and Indicator Systems Conference. St Andrews, Scotland: Centre for Public Policy and Management, University of St Andrews, pp. 86-95.

Davies, H. \& Powell, A., 2007. Healthcare professionals 'views on clinician engagement in quality improvement A literature review,

Department of Health, 2007. Rebuilding the NHS-A New Generation of Healthcare Facilities, Leeds, UK.

Eckert, C. \& Boujut, J., 2003. The role of objects in design co-operation: communication through physical or virtual objects. Computer Supported Cooperative Work, 12, pp.pp.145-151.

Ewenstein, B. \& Whyte, J., 2009. Knowledge Practices in Design: The Role of Visual Representations as 'Epistemic Objects'. Organization Studies, 30(1), pp.07-30.

Feldman, M.S. \& Orlikowski, W.J., 2011. Theorizing Practice and Practicing Theory. Organization Science, 22, pp.1240-1253.

Geiger, D., 2009. Revisiting the Concept of Practice: Toward an Argumentative Understanding of Practicing. Management Learning, 40(2), pp.129-144. 
Gorli, M., Nicolini, D. \& Scaratti, G., 2015. Reflexivity in practice: Tools and conditions for developing organizational authorship. Human Relations, pp.1-29.

Grix, J., 2010. The Foundations of Research, Palgrave Macmillan.

Hare, P., 2013. PPP and PFI: the political economy of building public infrastructure and delivering services. Oxford Review of Economic Policy, 29(1), pp.95-112.

Heidegger, M., 1929. Being and Time, Albany, New York, USA: SUNY Press.

Holland, W.W., 2010. Competition or collaboration? A comparison of health services in the UK. Clinical Medicine, 10(5), pp.431-433.

Hughes, R. \& Huby, M., 2002. The application of vignettes in social and nursing research. Journal of advanced nursing, 37(4), pp.382-386.

Jenkins, N. et al., 2010. Putting it in context: the use of vignettes in qualitative interviewing. Qualitative Research, 10(2), pp.175-198.

Johannessen, K., 1990. Rule Following, Intransive Understanding and Tacit Knowledge - An Investigation of the Wittgensteinian Concept of Practice as Regards Tacit Knowledge,

Kim, J. \& de Dear, R., 2013. Workspace satisfaction: The privacy-communication trade-off in open-plan offices. Journal of Environmental Psychology, 36, pp.18-26.

Lahlou, S., 2011. How can we capture the subject's perspective? An evidence-based approach for the social scientist. Social Science Information, 50(3-4), pp.607-655.

Littig, B., 2013. On high heels: A praxiography of doing Argentine tango. European Journal of Women's Studies, 20(4), pp.455-467.

Luck, R., 2010. Using objects to coordinate design activity in interaction. Construction Management and Economics, 28(6), pp.641-655.

Marshall, C. \& Rossman, G., 1989. Designing Qualitative Research, Newbury Park, CA, USA: Sage.

Marshall, N., 2014. Thinking, saying and doing in collaborative projects: What can we learn from theories of practice? Engineering Project Organization Journal, 4(2-3), pp.107122.

NHS Estates \& Department of Health Estates and Facilities, 2008. Achieving Excellence Design Evaluation Toolkit ( AEDET Evolution) Instructions, scoring and guidance,

NHS Estates; Department of Health Facilities and Estates, 2008. A Staff and Patient Environment Calibration Toolkit. Department of Health Website. Available at: http://www.http//webarchive.nationalarchives.gov.uk/20130107105354/http://www.dh.g ov.uk/en/Publicationsandstatistics/Publications/PublicationsPolicyAndGuidance/DH_08 2087 [Accessed October 27, 2014].

Nicolini, D., 2009. Articulating Practice through the Interview to the Double. Management Learning, 40(2), pp.195-212.

O'Keeffe, D.J., Thomson, D.S. \& Dainty, A.R.J., 2012. Beyond Scoring: advancing a new approach to the design evaluation of NHS buildings. In S. D. Smith, ed. Proceedings of 28th Annual ARCOM Conference. Edinburgh: Association Researchers in Construction Management, p. pp. 10.

Oswick, C., 2005. Boundary objects and organizational knowledge : A discursive perspective,

Parand, A. et al., 2014. The role of hospital managers in quality and patient safety: a systematic review. BMJ open, 4(9), p.e005055.

Paxman, J., 2014. "If I Were King for A Day." The Guardian. 
Perakyla, A., 2004. Reliability and validity in research based on naturally occuring social interaction. In D. Silverman, ed. Qualitative Research, Theory, Method and Practice. London UK: Sage Publications, Thousand Oaks, CA, USA, pp. 283-304.

Reckwitz, a., 2002. Toward a Theory of Social Practices: A Development in Culturalist Theorizing. European Journal of Social Theory, 5(2), pp.243-263.

Reckwitz, A., 2008. Praktiken und Diskurse: Eine sozialtheoretische und methodologische Relation. In H. Kalthoff, S. Hirschauer, \& L. G., eds. Theoretische Empirie. Die Relevanz qualitativer Forschung. Frankfurt am Main, Germany: Suhrkamp.

Reckwitz, A., 2002a. The Status of the " Material" in Theories of Culture : From "Social Structure " to " Artefacts ." Journal for the Theory of Social Behaviour, 32(2), pp.195217.

Reckwitz, A., 2002b. The Status of the "Material" in Theories of Culture: From "Social Structure" to "Artefacts,"

Sage, D., Dainty, A. \& Brookes, N., 2010. A consideration of reflexive practice within the critical projects movement. International Journal of Project Management, 28(6), pp.539-546.

Schatzki, T., Knorr Cetina, K. \& Von Savigny, E., 2001. The practice turn in contemporary theory T. Schatzki, K. Knorr Cetina, \& E. Von Savigny, eds., London, UK: Routledge.

Schatzki, T.R., 2005. Peripheral Vision: The Sites of Organizations. Organization Studies, 26(3), pp.465-484.

Schatzki, T.R., 2002. The Site of the Social, University Park, PA, USA: Pennsylvania State University Press.

Schmidt, K. \& Wagner, I., 2002. Coordinative artifacts in architectural practice. Design, (June), pp.257-274.

Schmidt, R. et al., 2012. Moving architecture and flattening politics: examining adaptability through a narrative of design. Architectural Research Quarterly, 16(01), pp.75-84.

Scottish Futures Trust, 2012. What can we do with the office?, Edinburgh, UK.

Sexton, M. \& Lu, S., 2009. The challenges of creating actionable knowledge: an action research perspective. Construction Management and Economics, 27(7), pp.683-694.

Shipton, C., Hughes, W. \& Tutt, D., 2014. Change management in practice: an ethnographic study of changes to contract requirements on a hospital project. Construction Management and Economics, 32(7-8), pp.787-803.

Snow, D.A., Morrill, C. \& Anderson, L., 2003. Elaborating analytic ethnography. Ethnography, 4(2), pp.181-200.

Star, S.L. \& Griesemer, J.R., 1989. Institutional Ecology, "Translations” and Boundary Objects: Amateurs and Professionals in Berkeley's Museum of Vertebrate Zoology, 1907-39. Social Studies Of Science, 19(3), pp.387-420.

The Department of Health, 2001. The NHS Plan, London UK.

Whitehead, T., 2002. WHAT IS ETHNOGRAPHY? Methodological, Ontological and Espistemological Attributes, Maryland, USA.

Whittington, R., 2006. Completing the Practice Turn in Strategy Research. Organization Studies, 27(5), pp.613-634.

Winter, M. \& Smith, C., 2006. Rethinking Project Management,

Zundel, M., 2012. Walking to learn: Rethinking reflection for management learning. Management Learning, 44(2), pp.109-126. 
Table 1: Fieldwork Observation Phases

\begin{tabular}{|c|c|c|c|}
\hline \multicolumn{2}{|c|}{$\begin{array}{l}\text { Procurement Phase } \\
\text { (and key participants) }\end{array}$} & \multirow{2}{*}{$\begin{array}{l}\text { Timeline } \\
\text { Sept } 2012 \\
\text { to } \\
\text { April } 2013\end{array}$} & \multirow{2}{*}{$\begin{array}{l}\text { Principal Design subsequent Design } \\
\text { Evaluation Activities } \\
\text { Agreed Concept Design } \\
\text { Develop Concept Design to submit for } \\
\text { Planning Permission in Principle }\end{array}$} \\
\hline $\mathrm{A}$ & $\begin{array}{l}\text { Pre Outline Business Case } \\
\text { (OBC) } \\
\text { (Project Team \& Advisors } \\
\text { \& End Users \& Scottish } \\
\text { Futures Trust (SFT)) }\end{array}$ & & \\
\hline$B$ & $\begin{array}{l}\text { Post OBC - OJEU } \\
\text { (Project Team \& Advisors } \\
\text { \& End Users \& SFT) }\end{array}$ & $\begin{array}{l}\text { April } 2013 \\
\text { to } \\
\text { June } 2013\end{array}$ & $\begin{array}{l}\text { Development of Concept Design to } \\
\text { produce a Reference Design to the } \\
\text { detail of: } 1: 200 \text { and } \\
\text { 1:50 scales plus } \\
\text { Clinical Policies }\end{array}$ \\
\hline $\mathrm{C}$ & $\begin{array}{l}\text { Pre-qualification } \\
\text { Questionnaire -Issue of } \\
\text { Invitation to Participate in } \\
\text { Dialogue (ITPD) } \\
\text { (Bid Evaluation Team \& } \\
\text { Advisors \& End Users \& } \\
\text { Scottish Futures Trust) }\end{array}$ & $\begin{array}{l}\text { June } 2013 \\
\text { to } \\
\text { October } 2013\end{array}$ & $\begin{array}{l}\text { Development of Tender Evaluation } \\
\text { Criteria (including Design Evaluation) } \\
\text { Finalise Reference Design and } \\
\text { Development of Revit Model }\end{array}$ \\
\hline $\mathrm{D}$ & $\begin{array}{l}\text { Competitive Dialogue } \\
\text { (Bid Evaluation Team \& } \\
\text { Advisors \& Bidders) }\end{array}$ & $\begin{array}{l}\text { October } 2013 \\
\text { to } \\
\text { June } 2014\end{array}$ & $\begin{array}{l}\text { Development of Reference Design by } \\
\text { Bidders with their own design solutions } \\
\text { Design Evaluation of Bidder's Design } \\
\text { by Bid Evaluation Team against the } \\
\text { Reference Design }\end{array}$ \\
\hline $\mathrm{F}$ & $\begin{array}{l}\text { Draft Final Tender } \\
\text { Evaluation } \\
\text { (Bid Evaluation Team \& } \\
\text { Advisors \& Bidders) }\end{array}$ & $\begin{array}{l}\text { June } 2014 \\
\text { to } \\
\text { July } 2014\end{array}$ & $\begin{array}{l}\text { Acceptance of Draft Final Tender and } \\
\text { Close of Dialogue }\end{array}$ \\
\hline $\bar{G}$ & $\begin{array}{l}\text { Final Tender Evaluation } \\
\text { (Bid Evaluation Team \& } \\
\text { Advisors) }\end{array}$ & $\begin{array}{l}\text { July } 2014 \\
\text { to } \\
\text { Sept } 2014\end{array}$ & $\begin{array}{l}\text { Finalisation of Bidder's Design to } \\
\text { comply with Board's Brief }\end{array}$ \\
\hline $\mathrm{H}$ & $\begin{array}{l}\text { Preferred Bidder to } \\
\text { Financial Close } \\
\text { (Bid Evaluation Team \& } \\
\text { Advisors \& Bidders \& End } \\
\text { Users) }\end{array}$ & $\begin{array}{l}\text { Sept } 2014 \\
\text { to (anticipated) } \\
\text { Jan } 2015\end{array}$ & $\begin{array}{l}\text { Sign-off of Bidder's Design (incl. } \\
\text { equipment) with End Users } \\
\text { Submission of Design for Full Planning } \\
\text { Approval } \\
\text { Design for Manufacture continuing } \\
\text { along with detailed design of building } \\
\text { services and structures }\end{array}$ \\
\hline
\end{tabular}

